\title{
GURU BERPRESTASI: PENGUATAN PENDIDIKAN DI ERA REVOLUSI INDUSTRI
}

\section{0}

\section{OUTSTANDING TEACHER: STRENGTHENING EDUCATION IN THE ERA OF INDUSTRIAL REVOLUTION 4.0}

\author{
R R Aliyyah'1a, M A Humaira1, S W Ulfah'1, M Ichsan'1 \\ 1Program Studi Pendidikan Guru Sekolah Dasar, Fakultas Keguruan dan Ilmu Pendidikan, \\ Universitas Djuanda Bogor \\ a Korespondensi: Megan Asri Humaira, E-mail: megan.asri@unida.ac.id \\ (Diterima:02-01-2020; Ditelaah: 02-01-2020; Disetujui: 12-03-2020)
}

\begin{abstract}
The teacher is a professional educator who educates, teaches a knowledge, guides, trains, gives assessments, and evaluates students. In this case, the teacher not only teaches formal education but also other education and can become a model modeled by his students. The role of the teacher is also very important in the process of creating the quality of the next generation of quality, both intellectually and morally. Due to this reason, teachers are needed to compete in the 4.0 industrial revolution. Research data obtained through interviews and documentation. In determining as an outstanding teacher, very tight competition is carried out with various aspects of assessment. The results of this study indicate that to become an outstanding teacher at least have certain criterias, such as teacher performance, scientific papers, and others.

Keywords: Education, elementary school, teacher achievement, teacher performance, teacher competence.
\end{abstract}

\begin{abstract}
ABSTRAK
Guru adalah pendidik profesional yang mendidik, mengajarkan pengetahuan, membimbing, melatih, memberikan penilaian, dan mengevaluasi siswa. Dalam hal ini, guru tidak hanya mengajar pendidikan formal, tetapi juga pendidikan lainnya dan dapat menjadi model yang dicontohkan oleh murid-muridnya. Peran guru juga sangat penting dalam proses menciptakan generasi kualitas berikutnya, baik secara intelektual maupun moral. Untuk alasan ini, guru diperlukan untuk bersaing dalam revolusi industri 4.0. Data penelitian diperoleh melalui wawancara dan dokumentasi. Dalam menentukan sebagai guru yang luar biasa, kompetisi yang sangat ketat dilakukan dengan berbagai aspek penilaian. Hasil penelitian ini menunjukkan bahwa untuk menjadi guru yang berprestasi setidaknya memiliki kriteria tertentu, seperti kinerja guru, memiliki karya tulis ilmiah, dan lain-lain.

Kata kunci: Guru berprestasi, kinerja guru, kompetensi guru, pendidikan, sekolah dasar.

Aliyyah, R. R., Humaira, M. A., Ulfah. S. W., \& Ichsan, M. (2020). Guru Berprestasi: Penguatan

Pendidikan di Era Revolusi Industri 4.0. Jurnal Sosial Humaniora, 11(1), 59-64.
\end{abstract}

\section{PENDAHULUAN}

Menurut Undang-Undang nomor 20 tahun 2003 tentang Sistem Pendidikan Nasional Pasal 1, mengenai ketentuan umum butir 6, pendidik adalah tenaga kependidikan yang berkualifikasi sebagai guru, dosen, konselor, pamong belajar, widyaiswara, tutor, instruktur, fasilitator, dan sebutan lain yang sesuai dengan kekhususannya, serta berpartisipasi dalam menyelenggarakan 
pendidikan. Berdasarkan UU tersebut maka dapat dikatakan bahwa guru adalah pendidik.

Guru juga dapat diartikan sebagai orang yang tugasnya terkait dengan upaya mencerdaskan kehidupan bangsa dalam semua aspeknya, baik spiritual dan emosional, intelektual, fisikal, maupun aspek lainnya (Suparlan, 2008). Adapun menurut Imran, guru adalah jabatan atau profesi yang memerlukan keahlian khusus dalam tugas utamanya seperti mendidik, mengajar, membimbing, mengarahkan, melatih, menilai, dan mengevaluasi siswa pada pendidikan anak usia dini jalur pendidikan formal, pendidikan dasar, dan menengah (Imran, 2010). Jika disimpulkan berdasarkan beberapa pengertian mengenai guru, maka guru adalah seorang pendidik yang tugas utamanya untuk mendidik, mengajar, membimbing, mengarahkan, melatih, menilai, dan mengevaluasi siswa pada pendidikan anak usia dini jalur pendidikan formal, pendidikan dasar, dan menengah, yang tujuan utamanya untuk mencerdaskan anak bangsa dalam semua aspek.

Dalam melaksanakan tugas utamanya tersebut, seorang guru harus memiliki kemampuan teknis edukatif serta harus memiliki kepribadian yang dapat menjadi panutan bagi siswanya maupun lingkungannya (Aliyyah, et al., 2019). Seperti yang dikatakan Direktur Jenderal Guru dan Tenaga Kependidikan, Supriano, keteladanan guru dan tenaga kependidikan (GTK) bagi murid dan lingkungannya merupakan kunci sukses dalam pencerdasan kehidupan bangsa (Umam, 2019). Hal tersebut memperjelas bahwa guru yang berprestasi dan berdedikasi dapat menjadi teladan yang baik bagi murid dan lingkungan ekosistem pendidikannya.

Di era revolusi industri 4.0 ini, sangatlah penting bagi dunia pendidikan untuk turut berkembang. Perkembangan tersebut memerlukan sistem pendidikan yang dapat membentuk generasi yang kreatif, inovatif, dan kompetitif. Salah satunya dapat dicapai dengan cara meningkatkan kinerja guru melalui program guru berprestasi. UndangUndang Republik Indonesia Nomor 14 Tahun 2005 tentang Guru dan Dosen, Pasal 36 ayat (1) yang menyatakan bahwa "Guru yang berprestasi, berdedikasi luar biasa, dan/atau bertugas di daerah khusus berhak memperoleh penghargaan. Kemudian berdasarkan Peraturan Pemerintah Republik Indonesia Nomor 74 Tahun 2008 Pasal 30 ayat (1) ditegaskan bahwa "Guru memiliki hak untuk mendapatkan penghargaan sesuai dengan prestasi kerja, dedikasi luar biasa, dan/atau bertugas di daerah khusus". Guru Berprestasi dapat menjadi guru model atau contoh bagi guru lainnya karena yang bersangkutan mempunyai prestasi yang luar biasa atau melebihi yang dicapai guru lain sehingga berdampak positif terhadap peningkatan mutu dan proses hasil pembelajaran menuju standar nasional pendidikan .

Persoalan yang muncul ialah bagaimana seorang guru dapat dikatakan berprestasi? Untuk itu, pemerintah khususnya Kementerian Pendidikan dan Kebudayaan (Kemendikbud) membuat program guru berprestasi dengan berbagai kriteria yang harus dipenuhi oleh setiap guru. Dengan adanya program tersebut, guru diharapkan mampu meningkatkan kualitas pendidikan sesuai zamannya atau dapat mengubah dunia pendidikan menjadi lebih baik lagi. Oleh karena itu, penelitian ini menjelaskan bagaimana menjadi guru yang berprestasi sebagai upaya penguatan pendidikan di era revolusi 4.0 .

\section{MATERI DAN METODE}

Penelitian ini menggunakan penelitian deskriptif kualitatif. Analisis dipaparkan dengan memberikan suatu deskripsi atau gambaran terkait fakta-fakta yang terjadi di lapangan khususnya mengenai guru kriteria guru berprestasi. Adapun data primer pada penelitian ini diperoleh melalui wawancara terhadap beberapa responden. Responden tersebut adalah kepala sekolah dan guru berprestasi (2017 dan 2018) di beberapa 
sekolah dasar, yakni SD Al-Izhar Pondok Labu (2017), SD Al Irsyad Al Islamiyyah (2017), SDN Menteng 03 (2018), SDN Sukasari 5 Tangerang (2018), dan SDN 023 Pajagalan (2018). Sementara itu, data penelitian juga didapat dari beberapa dokumen pendukung lainnya, seperti pedoman-pedoman terkait pemilihan guru berprestasi yang telah ditetapkan Kemendikbud, dan beberapa dokumen lainnya.

\section{HASIL DAN PEMBAHASAN}

Guru memiliki peran yang sangat penting dalam setiap proses pembelajaran. Guru juga berperan dalam perkembangan diri dan pengoptimalan bakat serta kemampuan masing-masing peserta didiknya. Hal ini sejalan dengan pengertian bahwa guru adalah seorang pendidik yang tugas utamanya untuk mendidik, mengajar, membimbing, mengarahkan, melatih, menilai, dan mengevaluasi siswa pada pendidikan anak usia dini jalur pendidikan formal, pendidikan dasar, dan menengah, yang tujuan utamanya untuk mencerdaskan anak bangsa dalam semua aspek.

Dalam upayanya meningkatkan kualitas pendidikan di Indonesia pada era revolusi industri 4.0 ini, guru dituntut untuk dapat membentuk peserta didik yang kreatif, inovatif, dan kompetitif. Untuk itu, pemerintah melalui Kemendikbud mengadakan program tahunan untuk memberikan apresiasi atau penghargaan kepada guru-guru yang berprestasi. Program guru berprestasi tersebut diadakan dengan tujuan untuk (a) mengangkat derajat guru sebagai profesi yang terhormat dan bermartabat, (b) meningkatkan motivasi dan profesionalisme guru dalam melaksanakan tugasnya, (c) meningkatkan kompetensi guru melalui kompetisi secara sehat dengan pemberian penghargaan di bidang pendidikan, (d) membangun komitmen guru dalam rangka meningkatkan mutu pembelajaran menuju standar nasional pendidikan, dan (e) membangun keteladanan guru terhadap peserta didik dan sesama guru dalam menghadapi abad ke-21 dan revolusi industri 4.0 (Direktorat Pembinaan Guru Pendidikan Dasar, 2019).

Persaingan yang kuat antar sekolah khususnya antar guru untuk memperoleh penghargaan sebagai guru berprestasi tidak dapat dihindari terutama di masing-masing sekolah yang menjadi objek penelitian ini, yakni SD Al-Izhar Pondok Labu (2017), SD $\mathrm{Al}$ Irsyad Al Islamiyyah (2017), SDN Menteng 03 (2018), SDN Sukasari 5 Tangerang (2018), dan SDN 023 Pajagalan (2018). Seperti yang disebutkan oleh Widodo, guru berprestasi adalah guru yang memiliki kinerja melampaui standar yang telah ditetapkan oleh satuan pendidikan, yang mencakup kompetensi pedagogik, kompetensi kepribadian, kompetensi profesional, kompetensi sosial dan mampu menghasilkan karya inovatif yang diakui baik pada tingkat daerah, nasional dan/atau internasional; dan secara langsung membimbing peserta didik hingga mencapai prestasi di bidang intrakurikuler dan/atau ekstrakurikuler (Widodo, 2009). Untuk itu, terdapat beberapa kriteria yang menjadi syarat utama bagi seorang guru untuk mendapatkan apresiasi atau penghargaan sebagai guru berprestasi tersebut, antara lain sebagai berikut.

\section{Persyaratan Akademik}

Peserta memiliki kualifikasi akademik minimal sarjana (S-1) atau diploma empat (DIV) sesuai dengan mata pelajaran di sekolah dasar. Peserta memiliki sertifikat pendidik, pada syarat akademik, terlihat sangat jelas bahwa syarat untuk menjadi seorang guru ialah memiliki kualifikasi akademik minimal S-1 atau D-IV sesuai dengan mata pelajaran yang diampunya. Selain itu, memiliki sertifikat pendidik juga menjadi syarat yang harus dipenuhi. Fakta seorang guru telah memiliki sertifikat pendidik ialah bahwa guru telah memiliki beberapa kompetensi guru. Diperolehnya sertifikat pendidik dapat menjadi modal awal seorang guru untuk 
dapat lebih mengembangkan dan meningkatkan lagi kinerja atau kompetensinya.

Kompetensi guru merupakan perpaduan kemampuan personal, keilmuan, teknologi, sosial, dan spiritual yang secara kaffah membentuk kompetensi standar profesi guru mencakup penguasaan materi, pemahaman peserta didik, pembelajaran mendidik, pengembangan pribadi dan profesionalisme (Mulyasa, 2009) (AO Sulaimani, PSA Sarhandi, \& MH Buledi, 2017). Kompetensi guru mempengaruhi tercapai tidaknya tujuan pembelajaran dan pendidikan di sekolah. Kompetensi guru dipengaruhi oleh latar belakang pendidikan, pengalaman mengajar, dan lamanya mengajar (Uno, Profesi kependidikan, 2011) (M. Bray, B. Adamson, \& M. Mason, 2014). Kompetensi guru merupakan gambaran hakikat kualitatif perilaku guru atau tenaga kependidikan (Uno, Model Pembelajaran, 2007) (AL Strauss, 1987). Standar kompetensi guru terdiri dari kompetensi pedagogik kompetensi kepribadian, kompetensi sosial dan kompetensi profesional (Menteri Pendidikan Nasional, 2007).

Persyaratan Administratif; Aktif melaksana kan proses pembelajaran; Mempunyai masa kerja sekurang-kurangnya 8 (delapan) tahun sebagai guru secara terus-menerus sampai saat diajukan sebagai calon peserta; Melaksana kan beban mengajar sekurang-kurangnya 24 jam per minggu; Melampirkan penilaian pelaksanaan pembelajaran dan kinerja guru (Penilaian kinerja guru)

Terdapat lebih dari 4 (empat) yang telah disebutkan terkait persyaratan administratif. Pada syarat ini, persyaratan yang paling menonjol ialah pada penilaian kinerja guru dengan pembobotan sebesar 25\%. Penilaian guru merupakan pengembangan dan pertumbuhan komprehensif. National Educational Association dalam Teacher assessment and Evaluation menyatakan "The core purpose of teacher assessment and evaluation should be to strengthen the knowledge, skills, dispositions, and classroom practices of professional educators. This goal serves to promote student growth and learning while also inspiring great teachers to remain in the classroom" (B. Bogdan \& SK Bilken, 1992). Adapun tujuan utama penilaian dan evaluasi guru adalah untuk memperkuat pengetahuan, keterampilan, disposisi dan praktek di kelas sebagai pendidik profesional (Aliyyah, et al., 2019). Pendapat lain mengatakan "Current policy discourse about teacher evaluation is mired in a rewards-and-punishment framework that too often aims to: 1) measure the effectiveness of each teacher, 2) categorize and rank teachers, 3) reward those at the top, and 4) fire those at the bottom.Such a simplistic approach not only ignores the complexity of teaching but also overlooks the real pur pose of teacher assessment and evaluation (PT $\mathrm{Ng}, 2015)$. Evaluasi guru ditujukan untuk mengukur efektifitas guru, mengkategori dan meranking guru, memberikan penghargaan bagi yang berprestasi, memberikan pendampingan kepada yang kurang memiliki kompetensi (Widyasari \& Yaumi, 2015) (Aliyyah, et al., 2019) (Aliyyah, et al., 2020).

Persyaratan Khusus membuat portofolio 3 (tiga) tahun terakhir: Membuat dan menyerahkan karya tulis ilmiah dalam bentuk laporan hasil penelitian atau laporan best practice beserta artikelnya yang merupakan hasil karya sendiri; Memiliki kinerja dan kompetensi minimal 'baik' dengan melampirkan hasil Penilaian Kinerja Guru (PKG) dan/atau tugas tambahan; Membuat dan menyerahkan video pembelajaran; Melampirkan deskripsi diri yang menjelaskan keunggulan dan kebanggaan pribadi guru sebagai pernyataan pengalaman terkait tugasnya sebagai guru.

Adapun syarat khusus yang merupakan kewajiban bagi guru berprestasi menunjukkan bahwa seorang guru dituntut untuk menghasilkan suatu karya yang kreatif dan inovatif khususnya di bidang pendidikan. 
Masing-masing kriteria tersebut wajib dipenuhi oleh masing-masing individu guru. Terdapat pembobotan pada masing-masing kriteria yang menunjukkan bahwa sebagai guru berprestasi memiliki kinerja melampaui standar yang telah ditetapkan oleh satuan pendidikan. Oleh karena itu, guru berprestasi dapat menjadi guru model atau contoh bagi guru lainnya karena yang bersangkutan mempunyai prestasi yang luar biasa atau melebihi yang dicapai guru lain sehingga berdampak positif terhadap peningkatan mutu dan proses hasil pembelajaran menuju standar nasional pendidikan.

\section{KESIMPULAN DAN IMPLIKASI}

Adanya program guru berprestasi dapat turut memperkuat pendidikan di era revolusi industri 4.0 ini. Hal tersebut dikarenakan dengan adanya kriteriakriteria agar dapat menjadi guru berprestasi, guru wajib meningkatkan dan mengembangkan kompetensi-kompetensi seorang guru yang juga dapat dilihat pada penilaian kinerja guru. Oleh karena itu, seorang guru berprestasi dengan memiliki kemampuan dalam melaksanakan tugasnya, memiliki kepribadian yang sesuai dengan profesi guru, serta memiliki wawasan kependidikan, mereka akan mampu meningkatkan mutu proses dan hasil pembelajaran atau bimbingan melebihi yang dicapai oleh guru lain sehingga dapat dijadikan panutan oleh siswa, rekan sejawat, maupun masyarakat sekitarnya, khususnya di lingkungan pendidikan.

\section{DAFTAR PUSTAKA}

AL Strauss. (1987). Analisis kualitatif untuk ilmuwan sosial.

Aliyyah, R. R., Widyasari, W., Rasmitadila, R., Ulfah, S. W., Humaira, M. A., \& Mulyadi, D. (2020, February). Outstanding Teachers' Competition: Between Strategies and Challenges. In 3rd International Conference on Research of Educational
Administration and Management (ICREAM 2019) (pp. 153-157). Atlantis Press.

Aliyyah, R. R., Widyasari, W., Rasmitadila, R., Humaira, M. A., Ulfah, S. W., \& Mulyadi, D. (2019). Outstanding Teachers: The Steps In Acquiring Them. International Journal for Educational and Vocational Studies, 1(5), 440-447.

Aliyyah, R. R., Widyasari, W., Mulyadi, D., Ulfah, S. W., \& Rahmah, S. (2019). Guru Berprestasi Sumber Daya Manusia Pengembang Mutu Pendidikan Indonesia. ALIGNMENT: Journal of Administration and Educational Management, 2(2), 157-165.

Aliyyah, R. R., Humaira, M. A., Mulyadi, D., Widyasari, Rasmitadila, \& Ulfah, S. W. (2019). Acquiring And Developing Outstanding Teachers Candidate: A Comparative Study From State And Private Elementary School. International Journal of Scientific \& Technology Research, 8(11), 1843-1847.

Aliyyah, R. R., Widyasari, Rasmitadila, Humaira, M. A., Ulfah, S. W., \& Mulyadi, D. (2019). Outstanding Teachers: The Steps In Acquiring Them. International Journal for Educational and Vocational Studies, 1(5).

AO Sulaimani, PSA Sarhandi, \& MH Buledi. (2017). Dampak pelatihan pengembangan profesional in-house CALL pada pedagogi guru: Sebuah studi evaluatif. Cogent Educ, 4(1), 1-13.

B. Bogdan, \& SK Bilken. (1992). Penelitian Berkualitas untuk Pendidikan: Pengantar Teori dan Metode.

Direktorat Pembinaan Guru Pendidikan Dasar. (2019). Pedoman Pemilihan Guru Sekolah Dasar Berprestasi Tingkat Nasional Tahun 2019. Jakarta: Kementerian Pendidikan dan Kebudayaan.

Imran. (2010). Pembinaan Guru Di Indonesia. Jakarta: Pustaka Jaya.

M. Bray, B. Adamson, \& M. Mason. (2014). Penelitian Pendidikan Komparatif, edisi ke-2. Londok, Inggris: Springer International Publishing.

Menteri Pendidikan Nasional. (2007). Standar Kualifikasi Akademik dan Kompetensi Guru . Jakarta: Kementerian Pendidikan Nasional Republik Indonesia.

Mulyasa. (2009). Standar Kompetensi dan Sertifikasi Guru. Remaja Rosda Karya. 
64 Aliyyah et, al.

PT Ng. (2015). “Apa itu pendidikan yang berkualitas? ? Bagaimana itu bisa dicapai ? Perspektif pemimpin menengah sekolah di Singapura".

Suparlan. (2008). Menjadi Guru Efektif. Jakarta: Hikayat Publishing.

Umam, C. (2019, Agustus 12). Kemendikbud Gelar Pemilihan Guru dan Tenaga Kependidikan Berprestasi dan Berdedikasi Tinggi 2019. Retrieved from Tribunnews.com:https://www.tribunnew s.com/nasional/2019/08/12/kemendikb ud-gelar-pemilihan-guru-dan-tenagakependidikan-berprestasi-danberdedikasi-tinggi-2019
Uno, H. B. (2007). Model Pembelajaran. Jakarta: Bumi Aksara.

Uno, H. B. (2011). Profesi kependidikan. Jakarta: Bumi Aksara.

Widodo, R. (2009, Agustus 18). Menjadi Guru Berprestasi. Retrieved from rachmadwidodo's weblog: https://wyw1d.wordpress.com/2009/08 /18/menjadi-guru-berprestasi/

Widyasari, \& Yaumi, M. (2015). Evaluasi Program Pendampingan Guru SD dalam Implementasi Kurikulum 2013. Lentera Pendidik, 17(2), 281-295. 